\title{
A Study on Paratexts in lan McEwan's Atonement
}

\author{
Weilong Huang ${ }^{1, \text { a }}$ \\ ${ }^{1}$ School of Foreign Languages, Neijiang Normal University, Neijiang 641199, China \\ ahuberthuang@126.com
}

Key words: Ian McEwan, Atonement, paratext, narrative theme, narrative structure

\begin{abstract}
The theory of paratext proposed by Gérard Genette integrates internal and external research and provides a valuable theoretical perspective and research paradigm for the study of novels. Ian McEwan's novel Atonement is interspersed with a variety of paratexts inclusive of title, title page and intertitles. They greatly facilitate the "presentation" of narrative structure, narrative theme and narrative technique in the text, and can be regarded a medium for the exchange between the author and the reader.
\end{abstract}

\section{Introduction}

The term "paratext" was first coined by the famous French literary theorist named Gerard Genette, who probed into the concept of it and expounded on how it related to a vast range of literary examples in his several works, including Palimpsestes: La littérature au second degré, Recherche de Proust and Paratexts: Thresholds of Interpretation, thus providing a new theoretical perspective and research paradigm for the study of novels. Genette pointed out that paratexts included "publisher's peritext, the name of the author, titles, the please-insert, dedications and inscriptions, epigraph, the prefatorial situation of communication, original preface and other prefaces, intertitles, the public epitext, the private epitext and so on". [1] He likened the "paratext" to the "threshold" that mediated between the text and what is external to the text, whose role was to "surround it and extend it, precisely in order to present it, in the usual sense of this verb but also in the strongest sense: to make present, to ensure the text's presence in the world, its 'reception' and consumption in the form (nowadays, at least) of a book." [2] Since the "threshold" mediates between the text and the author, and between the text and the reader, the main issue for the paratext is not to "look nice" around the text but rather to ensure for the text a destiny consistent with the author's purpose." [2] Meanwhile, the existence of paratext is to obtain the ideal reader, so that the ideal reader, with the textual prompts, can make out of the work's textual meaning and artistic intention as much as possible. Ian McEwan's Atonement consist of such paratexts as title, title page, intertitles and the like, which all appear to be marginal but assumes an important role in the presentation of the narrative structure, narrative theme and narrative technique.

\section{Title: Outline the Narrative Structure, Carry forward the Narrative Theme, and Highlight the Concern for the Sin of Humanity}

With the rise of modern literature, there come into being excellent literary works, and the titles of literary works, more often than not, are finished by the writer. In this context, there must be a proper title for a literary work that can be capable of accurately conveying the textual information and the author's intention, and providing readers with the "threshold" of the text. The title (of the modern literary text) grants a strong control over the text, and greater power to generalize the text, hence important functions of structure and interpretation." [3] It should be noticed that the title Atonement grants a strong control over the narrative theme since the narrative theme atonement is exactly consistent with the title. In this sense, the title is significant to the "presentation" of narrative theme.

The title Atonement is what first comes to the reader, aiming to ensure for the text a density that is consistent with McEwan's purpose. Based on the division of the title functions by Genette, the descriptive function of Atonement, which is a primary one, effectively conveys the information 
of the novel text. The four narrative parts are independent in terms of narrative perspective and narrative content, but they as a whole reflect the narrative structure of Atonement because the whole novel can be regarded as a typical Bildungsroman that starts with the roots and ends with routes of atonement.

The first part, with the alternative intersection of narrative perspectives of Briony and other characters, restores what was in the past and gives an account of the young Briony's crime, thus outlining her sin at individual level. The second part shifts to the root of atonement in the context of war with the exposure of ruthless war scenes through Robbie's perspective, which highlights the psychological trauma World War II brings to Robbie and other soldiers, and which depicts the collective evildoing on social dimension. As for the third part and the fourth one, they mainly focus on the routes of atonement. The third one tells of Briony's guiltiness in adulthood and her commitment to achieving atonement. Briony, as the implied author, ends this part with happy ends in which Cecilia and Robbie finally survive the Second World War and get together. The fourth part goes on with the route of atonement with the use of meta-narrative. In this part, Briony assumes the role of implied author of the novel, informing the reader of the truth that Robbie and Cecilia have lost their lives in World War II, and the happy ends of the novel turn out to be imaginary. Meanwhile, Briony always renews her draft until there would be no further draft, and always bear in mind their happy ends to achieve her atonement. To sum up, the four narrative parts seem to be separate, but they cling to the roots and routes of atonement structurally, which deepens the theme of atonements carried forward by the narrative work. Therefore, the title Atonement coincides with the text's narrative structure and narrative theme.

What is more, the title Atonement also bears implied function. As Patrick Fuery puts it, intertextuality is usually closely related to subject references. [4] By entitling the novel Atonement, McEwan makes reference to the biblical meaning of atonement, which serves as a metaphor for the prerequisite Christian view of original sin. In Christian culture, everyone is a sinner. It is best embodied in the work of Atonement, in which Briony's sin is a partial sin in the novel, and the theme of multiple sins found in the novel is equally thought-provoking. Indeed, Brinoy's accusation against Robbie is destructive to Robbie's life, but the whole social prejudice and secular bias against Robbie in view of his humble class origin, together with the unrecognized pure love between Cecilia and Robbie, suffice to make Robbie an ideal candidate for the "maniac" or the "culprit". In face of social and moral pressure, Briony is compelled to insist on her testimony in spite of her hesitation, which is as well an objective social reason for Robbie's imprisonment. Relative to individual tragedy as a result of social misreading, the tragedy of World War II is extremely brutal with unparalleled destruction, confirming the human nature of swelling hypocrisy and greed. Isn't it a sin indelible in human history? The title Atonement is a metaphor for the sinfulness of human nature advocated by Christian culture, which is consistent with the theme of atonement. Therefore, the universality of the original sin initiated by Christian doctrine coincides with the semantic diversity of sins disclosed by the text.

In terms of its metaphorical function, the title Atonement itself is intertwined with the Christian culture of the original sin in the Bible, which reflects the author's huge concern for the sin of human nature, and provides the medium for the reader to understand the textual meaning and the author's artistic intention.

\section{Quotes on Title Page: Arouse the Reader's Horizon of Expectation of Original Sin and Achieve the Presentation of "Sin"}

The title page is printed with quotes of another literary work. It is another important paratext conducive to the "presentation" of narrative theme. Throughout McEwan's later novels, the title pages of most works all witness the quotes from literary works. In Saturday, McEwan, in order to impart his writing intention, take an excerpt of Herzog as title page; in The Daydreamer, McEwan himself not only wrote a preface but also added "I want to speak about bodies changed into new forms" on title page, which referred to the Ovidius' Metamorphosis, in order to guide the reader to discover children's colorful imagination. The title page of Atonement refers to Jane Austin's 
Northanger Abbey. "Dear Miss Morland, consider the dreadful nature of the suspicions you have entertained. What have you been judging from? ... Could they be perpetrated without being known in a country like this, where social and literary intercourse is on such a footing, where every man is surrounded by a neighbourhood of voluntary spies, and where roads and newspapers lay everything open? Dearest Miss Morland, what ideas have you been admitting?”"[5]

McEwan's approach coincides with Genette's argument: a novel can also be a paratext of another novel as the "threshold" of the text. The quotes from Northanger Abbey are exactly the threshold of the text of Atonement since it guarantees a favorable interaction between the paratext and the reader and that between the paratext and the text. It is well known that the title cannot help the reader explore into the implications contained in the work, so the title page, functionally similar to the paratext of preface, aims at text interpretation. With what is implied on title page, the reader can more be easily accessible to the textual implication or the intention of the author. The title page, as a special tip given by McEwan, no doubt opens a channel for the reader to approach the text of the novel in a better way. The quotes on title page will allow the reader to produce a "horizon of expectation" before the reading of the text. The notion of the "horizon of expectation", which was proposed by Jauss, the theoretical representative of reception theory, suggests as follows: "A literary work, even if it seems new, does not appear as something absolutely new in an informational vacuum, but predisposes its readers to a very definite type of reception by textual strategies, overt and covert signals, familiar characteristics or implicit allusions." [6] The quotes on title page provide the "ideal reader" with a literary expectation horizon bordering on "aesthetic experience". In Atonement, the title page quotes focus on Henry's critical comment on Catherine Morland's dreadful nature of her Gothic imagination. In Northanger Abbey, Miss Morland, whose love of Gothic novels reduces her into the world of Gothic suspicion, suspects Henry, the innocent and virtuous man, of murdering his wife. Briony's unbounded imagination is equally transformed to destructive power. Morland and Briony, the two literary figures, bear resemblance in their mutual love of literature and their indulgence in literary imagination, which is disturbing and dreadful. By means of this special paratext of title page, McEwan opens the reader's horizon of expectation and sets the tone for Briony's character defect-related "crime".

\section{Multi-level Intertitles: the "Threshold" for the Construction of Textual Meaning and the Paratext Indicative of Complex Narrative Strategy}

The novel is characteristic of intertitles at different levels, including "Part One", "Part Two", "Part Three", "London, 1999" and 14 headings (from "Chapter 1" to "Chapter 14") in "Part One". As mentioned above, the title Atonement is significant to the "presentation" of the text, whereas "Part One" and its 14 headings reveal of little textual information, so the reader can not directly deduce the textual intent of the first part simply from the literal meaning of these headings. On surface, these headings arranged are a little wordy, but they allow the reader to construct their cognition about the narrative techniques of the text. This also reflects McEwan's originality in narrative strategy. "Part One", instead of adopting an omniscient narrative perspective, narrates the story from third person internal focalization by different characters, hence the headings of 14 chapters. With the constant shifts of third person internal focalization, the reader has to work out the narrative meaning in complex narrative structure until the reader gradually perceives the complex internal focalization and construct their understanding about narrative significance.

Indeed, McEwan requires active readers to participate in the construction of the meaning of the text. Of course, this initiative is inseparable from the well-designed chapter layout. If the headings of 14 chapters were all deleted, the boundaries of multiple internal focalization would be removed, which is not conducive to the communication of author's narrative strategy with the reader or to the construction of the textual meaning by the reader. Therefore, the fourteen chapters as a paratext facilitate the "presentation" of the complex narrative strategy in Part One, and constitute the important clues reserved for the reader to understand the narrative structure and actively construct the textual meaning. 


\section{Summary}

The paratexts of Atonement consist of title, title page, intertitles, all of which are "marginal text". The title Atonement coincides with and deepens the text's narrative structure and narrative theme. In addition, the title Atonement is intertwined with the Christian culture of the original sin in the Bible, which reflects the author's huge concern for the sin of human nature. The quotes of the title page stimulate readers' anticipation of Briony's "original sin", and the quotes as a paratext play an important role in the "presentation" of the "sin". The intertitles are consistent with the complex narrative strategy adopted in the text, serving as the "threshold" of textual meaning. In summary, they greatly facilitate the "presentation" of narrative structure, narrative theme and narrative technique in the text, and can be regarded a medium for the exchange between the author and the reader.

\section{Acknowledgements}

This work was financially supported by "The Project for the Reform of Neijiang Normal University in Teaching and Education (JG201515-293)”.

\section{References}

[1] Zhu Taoxiang, "The Value of Narrative Poetics of Paratexts to the Interpretation of Complex Texts,” Jiangxi Social Sciences, 2009 (04): 39.

[2] G. Genette, Paratexts: Thresholds of Interpretation, Trans. Jane E. Lewin, New York: Cambridge University Press, 1997: 1-407.

[3] Jing Hongyu, “On Paratexts in Modern Chinese Literature,” Social Sciences in China, 2012 (06): 175.

[4] P. Fuery, New Development in Film Theory, Trans. Li Ershi, Beijing: China Film Publishing House, 2004: 54.

[5] I. McEwan, Atonement, London: Jonathan Cape, 2001.

[6] H. Jauss, "Literary History as a Challenge to Literary Theory," New Literary History 2.1(1970): 7-37. 